\title{
Three Times Repeated Portal Venous Gas after Meals
}

\author{
Takamasa Kobayashi ${ }^{1}$, Atsunori Tsuchiya ${ }^{1}$, Takeshi Suda ${ }^{2}$ and Shuji Terai ${ }^{1}$
}

Key words: portal venous gas, chronic mesenteric ischemia, capsule endoscopy

(Intern Med 55: 843-845, 2016)

(DOI: 10.2169/internalmedicine.55.6036)

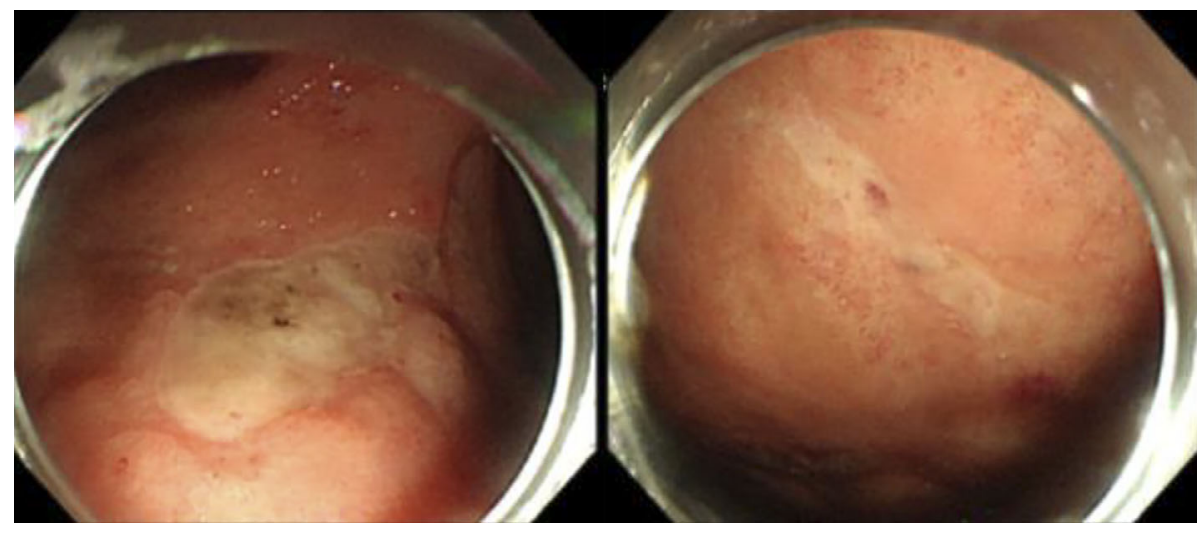

Picture 1.

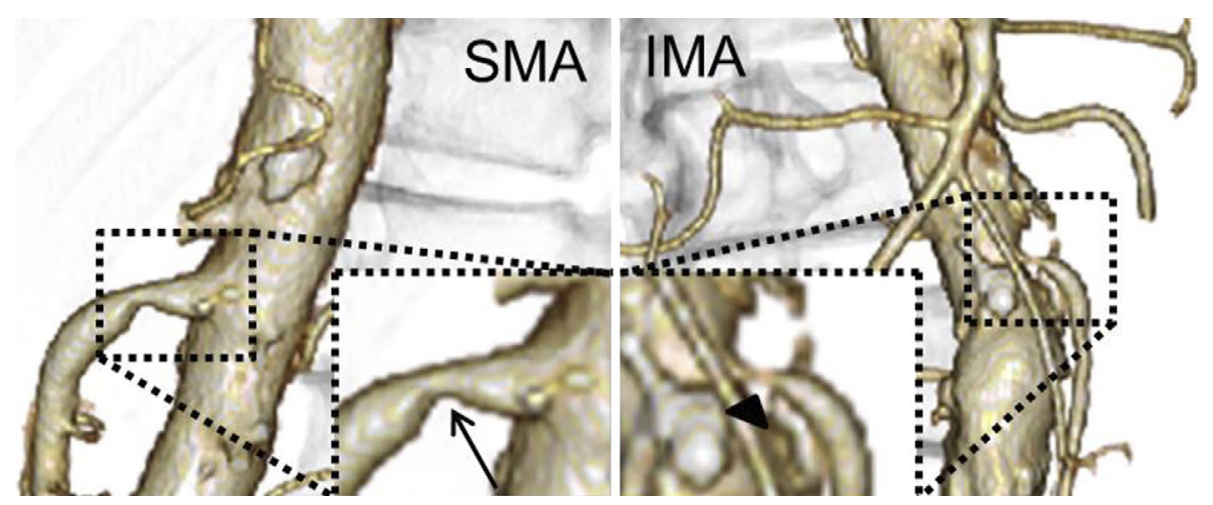

Picture 2.

A 62-year-old man was admitted due to long-shallow gastric ulcers (Picture 1). He was on various medications including warfarin. After admission, during which warfarin was stopped, he had a mild cerebral infarction, thus a heparin infusion was started (12,000 U/day). On day 20 he resumed meals and had short-term periumbilical pain. Computed tomography revealed portal venous gas (PVG) that disappeared the next day without intestinal ischemic change, and severe arteriosclerotic stenoses at both trunks of the superior- and inferior-mesenteric artery (SMA and IMA) (Picture 2). While the heparin dose was increased to 18,000 U/day, the same episode occurred two more times (Picture 3).

Since capsule endoscopy after the third PVG showed multiple ischemic areas in the distal jejunum (Picture 4; upperpanels), oral administration of clopidogrel and beraprost so-

${ }^{1}$ Department of Gastroenterology and Hepatology, Graduate School of Medical and Dental Science, Niigata University, Japan and ${ }^{2}$ Department of Gastroenterology and Hepatology, Uonuma Institute of Community Medicine, Niigata Medical and Dental Hospital, Japan Received for publication June 24, 2015; Accepted for publication July 20, 2015

Correspondence to Dr. Atsunori Tsuchiya, atsunori@med.niigata-u.ac.jp 


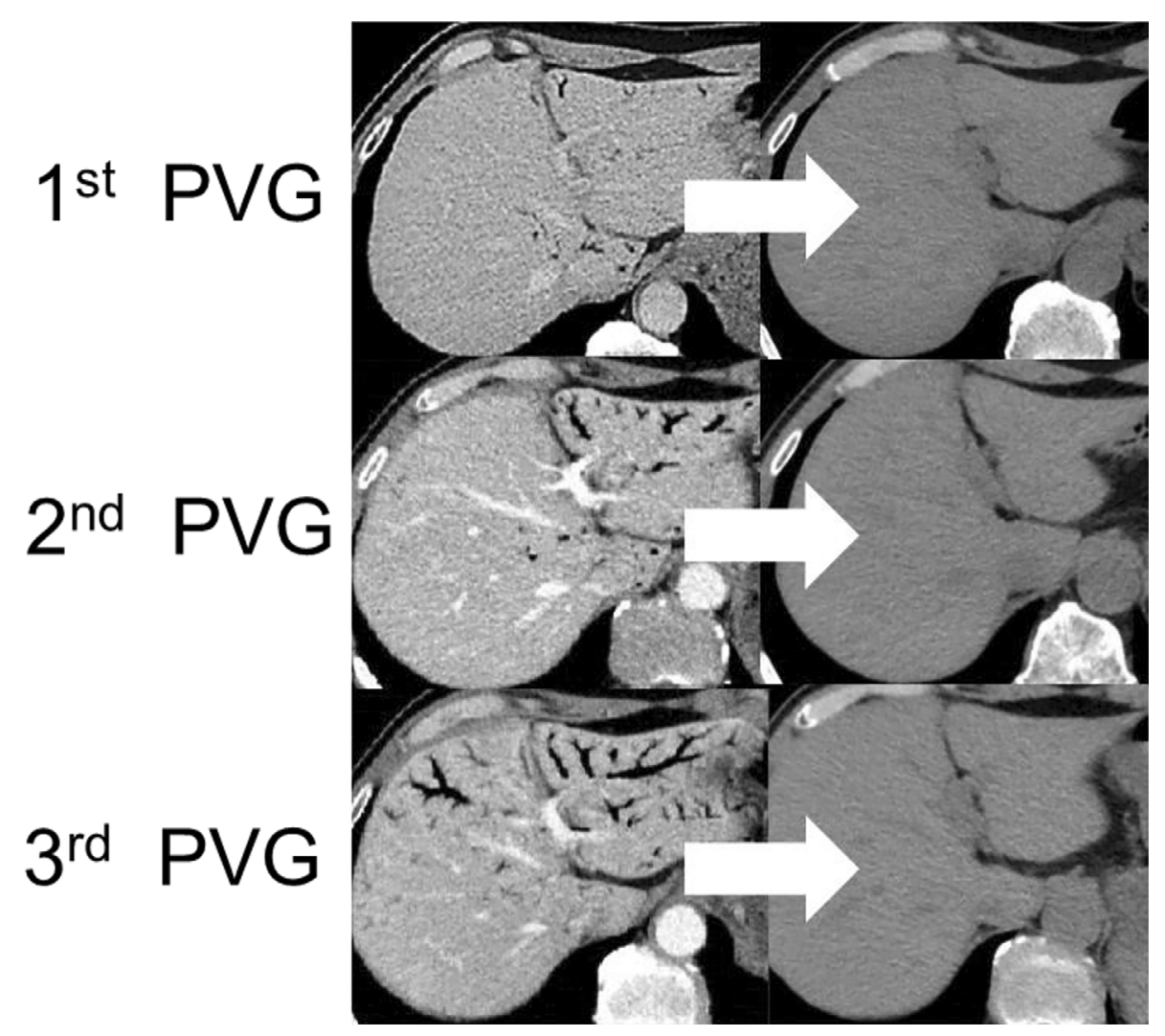

Picture 3.

\section{Capsule endoscopy}

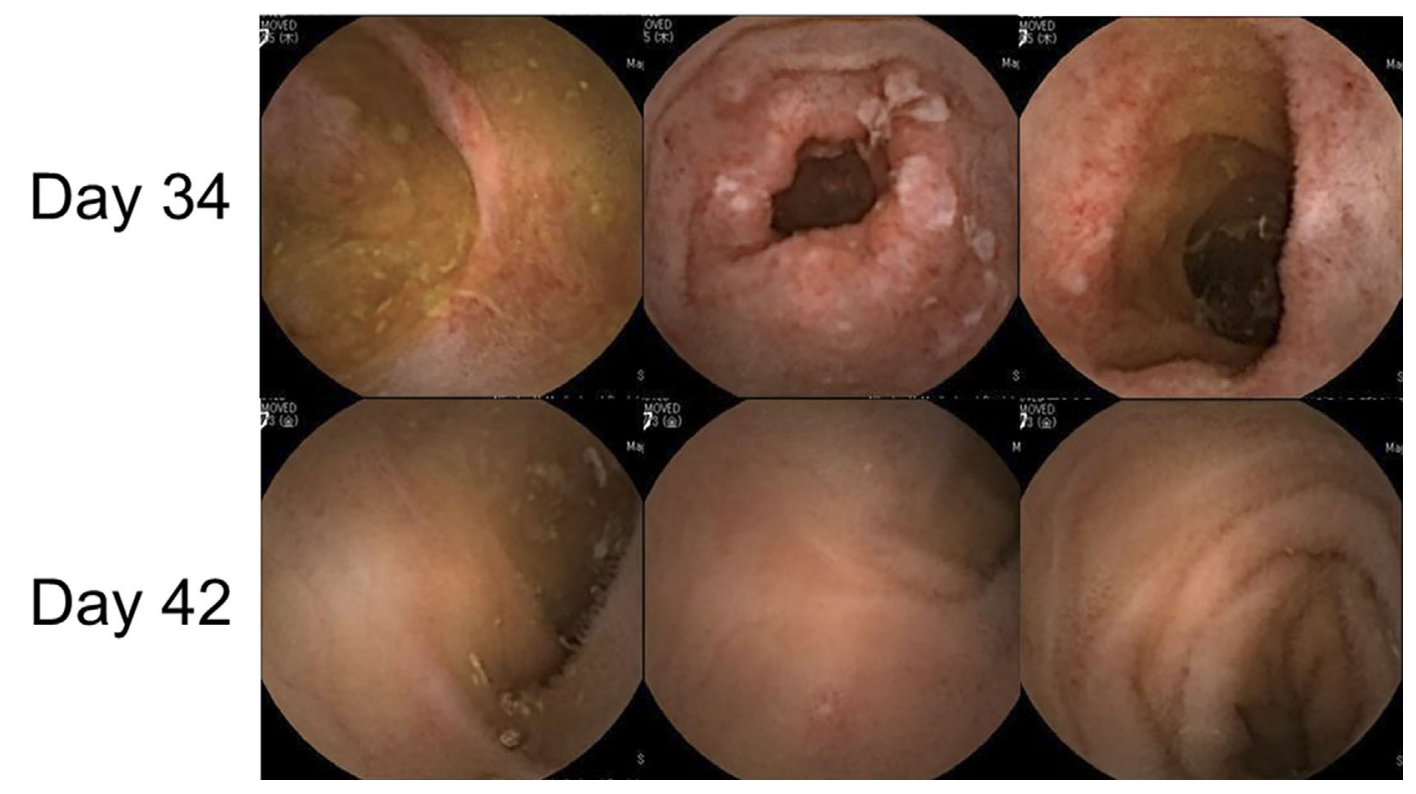

Picture 4.

dium was initiated, and the attack subsequently disappeared for more than one year (Picture 4; lower-panels). These clinical findings suggested that relative ischemia of the intestine after meals caused erosions/ulcers from where intestinal gas flowed into the portal vein.

This case clearly showed a reversible "chronic mesenteric ischemia-ischemic enteritis-PVG" sequence $(1,2)$. Antiplatelet and anti-coagulant therapies have a dual nature. While these drugs can lead to a risk of bleeding from damaged erosions/ulcers, these drugs can also prevent/improve this mucosal damage. 
Author's disclosure of potential Conflicts of Interest (COI). Shuji Terai: Honoraria, Otsnka Pharmaceutical.

\section{References}

1. Keese M, Schmitz-Rixen T, Schmandra T. Chronic mesenteric ischemia: time to remember open revascularization. World J Gastroenterol 19: 1333-1337, 2013.

2. Rankin I, Sheth H. Hepatic portal venous gas: comparison of two cases. Case Rep Surg 2013: 637951, 2013.

(C) 2016 The Japanese Society of Internal Medicine http://www.naika.or.jp/imonline/index.html 